\title{
PENGARUH TUMBUHAN KABOMBA (Cabomba aquatica Aubl.) TERHADAP KADAR TSS, DO dan COD LIMBAH CAIR LABORATORIUM KIMIA FMIPA UNTAN
}

\author{
Hanafi Afriza, Mukarlina ${ }^{1}$, Diah Wulandari Rousdy ${ }^{1}$ \\ ${ }^{1}$ Program Studi Biologi, Fakultas MIPA, Universitas Tanjungpura, Jl. Prof. Dr. H. Hadari Nawawi, Pontianak \\ Email korespondensi : john.hanafi@gmail.com
}

\begin{abstract}
Laboratory is one of the producers of waste water with a high content of hazardous materials before being discharged into water bodies. One effort to process laboratory waste with phytoremediation is to use Kabomba plants (Cabomba aquatica Aubl). This study aims to determine the ability of Kabomba (Cabomba aquatica Aubl.) To see the influence of plants on the levels of Total Suspended Solid (TSS), Dissolved Oksigen (DO) and Chemical Oxygen Demand (COD) from the Untreated Chemistry Laboratory Liquid Waste of FMIPA. This study used a Completely Randomized Design consisting of five treatments of waste concentration: control, 25, 50, 75, 100\%. Based on the results of the study, Cabomba plants (Cabomba aquatica, Aubl.) able to reduce TSS values by $37.67 \%$ and increase DO values by a percentage of $77.5 \%$ on day 5 of treatment but not yet able to reduce COD values and increase $\mathrm{pH}$ values
\end{abstract}

Keywords : Kabomba (Cabomba aquatica Aubl), Laboratory Liquid Waste, COD, DO, TSS

\section{PENDAHULUAN}

Laboratorium merupakan salah satu penghasil air limbah dengan kandungan bahan-bahan berbahaya yang cukup tinggi, sehingga diperlukan proses pengolahan sebelum dibuang ke badan air agar tidak mencemari lingkungan. Saat ini sebagian besar air limbah laboratorium khususnya yang berada di perguruan tinggi di Indonesia tidak diolah dengan baik. Berdasarkan sifat dan karakteristiknya limbah cair laboratorium termasuk dalam kategori limbah bahan berbahaya dan beracun (B3) (Suprihatin \& Siswi 2010). Limbah cair laboratorium sebagian besar mengandung logam berat dan mempunyai nilai BOD (Biological Oxygen Demand) dan COD (Chemical Oxygen Demand) yang tinggi. Tingginya nilai BOD, COD, dan logam berat dalam limbah cair laboratorium disebabkan oleh pemakaian bahan-bahan kimia selama kegiatan di laboratorium (Trisnawati et al., 2016; Rohaeti et al., 2011). Limbah laboratorium juga mengandung zat padat terlarut (TDS), zat padat tersuspensi (TSS) dan derajat keasaman $(\mathrm{pH})$ (Hartini et al. 2011).
Laboratorium Jurusan Kimia FMIPA Untan memiliki permasalahan dengan adanya limbah cair baik dari hasil praktium maupun penelitian. Jurusan Kimia FMIPA Untan mempunyai lima laboratorium dan belum memiliki Instalasi Pengolahan Air Limbah (IPAL). Selama tahun 2002-2017 air limbah laboratorium Jurusan Kimia FMIPA Untan hanya disimpan di dalam wadah berupa drum besar berdasarkan sifatnya (asam, basa, organik dan logam) tanpa pengolahan lebih lanjut.

Fitoremediasi merupakan suatu proses mendegradasi, menghilangkan, menstabilkan atau menghancurkan bahan pencemar dengan memanfaatkan tumbuhan (Kvesitadze et al., 2006). Menurut penelitian Widyawati (2014), kegiatan di UPT. Lab Analitik Universitas Udayana rata-rata menghasilkan limbah cair sebanyak $50 \mathrm{~L}$ /hari dengan nilai $\mathrm{pH}$ sebesar 1,05 nilai COD sebesar 86,1056 mg/L dan BOD sebesar 29,3888 mg/L. Hasil penelitian Tati (2017) juga menyatakan bahwa $H$. verticillata memiliki kemampuan mengurangi TSS sebesar $80,63 \%$ pada air limbah industri tahu. 
Kabomba (Cabomba aquatica Aubl.)) merupakan salah satu tumbuhan air dari famili Cabombaceae, diduga memiliki potensial digunakan sebagai objek fitoremediasi dalam menstabilkan air limbah karena sifat hidup tumbuhan kabomba submerged (terendam). Penelitian ini bertujuan untuk melihat pengaruh tumbuhan Kabomba (Cabomba aquatica Aubl.) terhadap kadar TSS, DO, dan COD pada air limbah laboratorium Kimia FMIPA UNTAN.

\section{BAHAN DAN METODE}

\section{Waktu dan Tempat Penelitian}

Penelitian ini dilakukan pada bulan Juni sampai Agustus 2018 di Laboratorium Biologi, Jurusan Biologi Fakultas Matematika dan Ilmu Pengetahuan Alam Universitas Tanjungpura Pontianak. Analisis kadar TSS, DO, dan COD di dilakukan di Rumah Kasa Biologi FMIPA UNTAN.

\section{Bahan}

Bahan-bahan yang digunakan dalam penelitian ini adalah sampel air limbah Laboratorium Kimia FMIPA Untan, asam sulfat $\left(\mathrm{H}_{2} \mathrm{SO}_{4}\right)$, fero ammonium sulfat (FAS), indikator ferroin, kalium dikromat $\left(\mathrm{K}_{2} \mathrm{Cr}_{2} \mathrm{O}_{7}\right)$, kalium hidroksida $(\mathrm{KOH})$, kalium iodida (KI), mangan sulfat $\left(\mathrm{MnSO}_{4}\right)$ merkuri sulfat $\left(\mathrm{HgSO}_{4}\right)$, natrium tiosulfat $\left(\mathrm{Na}_{2} \mathrm{~S}_{2} \mathrm{O}_{3}\right)$ dan perak sulfat $\left(\mathrm{Ag}_{2} \mathrm{SO}_{4}\right)$.

\section{Metode Penelitian}

Penelitian ini menggunakan Rancangan Acak Lengkap (RAL) dengan lima perlakuan konsentrasi limbah cair laboratorium, yaitu $0 \%$ (P1), 25\% (P2), 50\% (P3), 75\% (P4) dan 100\% (P5). Masing-masing perlakuan dilakukan pengulangan sebanyak 4 kali sehingga diperoleh 20 unit percobaan.

\section{Prosedur Kerja}

\section{Persiapan Tanaman Uji dan Media Uji}

Tanaman uji Kabomba (C. aquatica) diambil dari lingkungan alaminya yaitu perairan Desa Rasau Jaya. Tanaman uji yang diperoleh diaklimasi selama 7 hari kemudian ditambahkan nutrisi dengan larutan pupuk hidroponik. Setelah masa aklimasi, tanaman dipilih pada bagian batang yang tiap ruasnya telah tumbuh akar, segar, tidak terdapat daun yang rusak atau menguning memiliki berat segar yang sama \pm 100 gram untuk diaplikasikan pada perlakuan (Juswardi et al., 2010). Media uji air limbah laboratorium ditempatkan dalam wadah plastik berisi 5 liter air limbah. Pemaparan limbah cair laboratorium selama 10 hari.

\section{Total Suspended Solid (TSS)}

Total Suspended Solid (TSS) dihitung menggunakan metode gravimetri. Kertas saring dibersihkan dengan akuades. Kertas saring dioven selama 1 jam pada suhu $105^{\circ} \mathrm{C}$, masukkan ke desikator selama 15 menit, ditimbang, lakukan duplo (A). Sampel $100 \mathrm{ml}$ disaring, masukkan kertas saring ke dalam oven selama 1 jam pada suhu 1050C. Masukkan ke desikator 15 menit, timbang, lakukan duplo (B). Hasil yang diperoleh dihitung dengan rumus:

$$
\operatorname{TSS}(\mathrm{mg} / \mathrm{L})=\frac{(\mathrm{A}-\mathrm{B}) \times 1000}{\text { volume sampel }(\mathrm{mg} / \mathrm{l})}
$$

\section{Dissolved Oksigen (DO)}

Oksigen terlarut diukur dengan menggunakan metode Winkler. Media uji diambil, ditambahkan $1 \mathrm{~mL} \mathrm{MnSO}_{4}$ dan $1 \mathrm{~mL}$ KOH-KI kemudian dikocok dan didiamkan. Endapan putih/coklat yang terbentuk ditambahkan $1 \mathrm{ml} \mathrm{H}_{2} \mathrm{SO}_{4}$, dikocok lalu didiamkan. Larutan yang berwarna coklat diambil sebanyak $100 \mathrm{ml}$ kemudian ditetesi $\mathrm{Na}_{2} \mathrm{~S}_{2} \mathrm{O}_{3}, 0,025 \mathrm{~N}$. Larutan berwarna kuning pucat ditambahkan 5 tetes amilum. Larutan berwarna biru yang terbentuk dititrasi dengan $\mathrm{Na}_{2} \mathrm{~S}_{2} \mathrm{O}_{3}, 0,025 \mathrm{~N}$, kemudian terbentuk larutan bening. Volume $\mathrm{Na}_{2} \mathrm{~S}_{2} \mathrm{O}_{3}$, yang terpakai dihitung untuk mengetahui nilai DO dengan rumus:

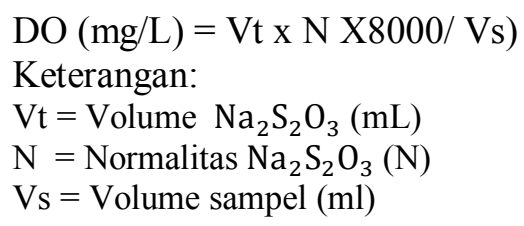

\section{Chemical Oxygen Demand (COD)}

Nilai COD diukur menggunakan metode spektofometri. Sebanyak $10 \mathrm{ml}$ sampel uji dipipet ke dalam erlemneyer $250 \mathrm{ml}$, ditambahkan $0,2 \mathrm{mg}$ $\mathrm{HgSO}_{4}$ dan $5 \mathrm{~mL}$ larutan $\mathrm{K}_{2} \mathrm{Cr}_{2} \mathrm{O}_{7}$. Kemudian ditambahkan $15 \mathrm{ml}$ reagen $\mathrm{H}_{2} \mathrm{SO}_{4}$ dan $\mathrm{Ag}_{2} \mathrm{SO}_{4}$ sambil didinginkan dalam air. Setelah itu didihkan diatas hot plate selama 2 jam, kemudian setelah dingin ditepatkan sampai volume $70 \mathrm{~mL}$. Kemudian setelah dibiarkan dingin ditambahkan 2-3 tetes indikator ferroin dan dititrasi dengan larutan Ferro Ammonium Sulfat (FAS) sampai warna larutan menjadi merah kecokelatan. Selanjutnya dihitung untuk mengetahui nilai COD dengan rumus:

$$
\operatorname{COD}\left(\mathrm{mg} \mathrm{O}_{2} / \mathrm{L}\right)=\frac{(\mathrm{A}-\mathrm{B}) \times \mathrm{N} \times 8000}{\mathrm{~mL} \text { sampel }}
$$


Keterangan :

$\mathrm{a}=\mathrm{ml}$ FAS yang digunakan untuk titrasi blanko $(\mathrm{mL})$

$\mathrm{b}=\mathrm{ml}$ FAS yang digunakan untuk titrasi sampel $(\mathrm{mL})$

$\mathrm{N}=$ Normalitas FAS

\section{Paramater Penelitian}

Parameter yang akan diukur pada penelitian ini adalah faktor lingkungan meliputi $\mathrm{pH}$ media uji, suhu media uji, kandungan Total Suspended Solid (TSS), Dissolved Oksigen (DO) dan Chemical Oxygen Demand (COD) pada air limbah. Pengukuran parameter TSS, DO dan COD dilakukan pada hari ke 0, 5 dan 10.

\section{Analisis Data}

Data hasil pengukuran TSS, DO, dan COD air limbah dianalisis secara statistik menggunakan Analisis Varian (Anava) satu jalur dengan SPSS 18. Jika terdapat perbedaan yang nyata akan dilakukan uji lanjut menggunakan uji Duncan pada selang kepercayaan 95\% (Hanafiah, 2004)

\section{HASIL DAN PEMBAHASAN}

\section{Hasil}

Hasil uji Anava pada hari ke-5 menunjukkan bahwa perlakuan dengan kabomba berpengaruh nyata terhadap penurunan TSS limbah cair laboratorium $(\mathrm{F}=29,085 p=0,000$; Anava). Hasil uji Anava pada hari ke-10 menunjukkan bahwa perlakuan kabomba ( $C$. aquatica) berpengaruh nyata terhadap peningkatan TSS limbah cair laboratorium ( $\mathrm{F}=6,771 p=0,003$; Anava).

Hasil pengukuran TSS setelah perlakuan selama 5 hari mengalami penurunan dengan kisaran persentase antara 29,36\%- 37,67\%. Konsentrasi perlakuan $25 \%$ mengalami penurunan TSS tertinggi sebesar $37,67 \%$ dan konsentrasi perlakuan $100 \%$ mengalami penurunan TSS terendah sebesar $29,36 \%$. Hasil pengukuran TSS mengalami kenaikan pada hari terakhir perlakuan (hari ke-10) menjadi 8,00-47,75 $\mathrm{mg} / \mathrm{L}$ dengan persentase kenaikan sebesar 42,73\%-160,06\% (Tabel 1).

Tabel 1. Rerata Nilai TSS limbah cair laboratorium pada hari

\begin{tabular}{cccc}
\hline Konsentrasi & \multicolumn{3}{c}{ Nilai TSS (mg/L) } \\
\cline { 2 - 4 } $\begin{array}{c}\text { Perlakuan } \\
(\%)\end{array}$ & Hari Ke-0 & Hari ke-5 & Hari ke-10 \\
\hline 0 & $8,7 \pm 0,95^{\mathrm{a}}$ & $5,75 \pm 0,95^{\mathrm{a}}$ & $8,00 \pm 0,81^{\mathrm{a}}$ \\
25 & $15,25 \pm 1,25^{\mathrm{b}}$ & $9,50 \pm 1,29^{\mathrm{b}}$ & $15,50 \pm 6,75^{\mathrm{a}}$ \\
50 & $23,25 \pm 1,25^{\mathrm{c}}$ & $15,75 \pm 2.21^{\mathrm{c}}$ & $40,25 \pm 1,50^{\mathrm{b}}$ \\
75 & $28,75 \pm 4,03^{\mathrm{d}}$ & $19,75 \pm 1,70^{\mathrm{c}}$ & $37,50 \pm 10,97^{\mathrm{b}}$ \\
100 & $36,25 \pm 3,50^{\mathrm{e}}$ & $25,25 \pm 2,75^{\mathrm{d}}$ & $47,75 \pm 14,05^{\mathrm{b}}$ \\
\hline \multicolumn{4}{c}{ ke-5 dan hari ke-10 perlakuan. }
\end{tabular}

Keterangan : Angka-angka pada yang sama dan diikuti oleh huruf kecil yang berbeda menunjukkan pengaruh yang nyata pada uji Duncan, taraf uji $95 \%$.

Hasil analisis Anava hari ke-5 menunjukkan bahwa perlakuan kabomba berpengaruh nyata terhadap kadar DO ( $\mathrm{F}=15,674 \mathrm{p}=0,000$; Anava). Semua perlakuan berbeda nyata dengan kontrol. Konsentrasi perlakuan $25 \%$ pada hari ke-5 berbeda nyata dengan konsentrasi perlakuan $100 \%$ tetapi tidak berbeda nyata dengan konsentrasi perlakuan $50 \%$.

Tabel 2. Rerata Dissolved Oxygen (DO) limbah cair laboratorium setelah 10 hari perlakuan.

\begin{tabular}{|c|c|c|c|}
\hline $\begin{array}{l}\text { Konsentrasi } \\
\text { Perlakuan } \\
(\%)\end{array}$ & H ke- 0 & $\begin{array}{l}\text { Nilai DO } \\
(\mathrm{mg} / \mathrm{L}) \\
\text { H ke- } 5\end{array}$ & H ke- 10 \\
\hline 0 & $4,20 \pm 0,36^{b}$ & $5,45 \pm 0,60^{\mathrm{c}}$ & $2,90 \pm 0,84^{b}$ \\
\hline 25 & $2,00 \pm 0,32^{\mathrm{a}}$ & $3,55 \pm 0,34^{b}$ & $1,85 \pm 0,44^{\mathrm{a}}$ \\
\hline 50 & $1,85 \pm 0,19^{\mathrm{a}}$ & $3,10 \pm 0,88^{\mathrm{ab}}$ & $1,70 \pm 0,25^{\mathrm{a}}$ \\
\hline 75 & $2,00 \pm 0,32^{\mathrm{a}}$ & $2,70 \pm 0,57^{\mathrm{ab}}$ & $1,85 \pm 0,19^{\mathrm{a}}$ \\
\hline 100 & $1,75 \pm 0,30^{\mathrm{a}}$ & $2,45 \pm 0,44^{\mathrm{a}}$ & $1,60 \pm 0,28^{\mathrm{a}}$ \\
\hline Keter & \multicolumn{3}{|c|}{$\begin{array}{l}\text { Angka-angka pada yang sama dan diikuti oleh } \\
\text { huruf kecil yang berbeda menunjukkan } \\
\text { pengaruh yang nyata pada uji Duncan, taraf uji } \\
95 \% \text {. }\end{array}$} \\
\hline
\end{tabular}

Nilai Dissolved Oxygen (DO) mengalami kenaikan pada hari ke-5 dengan kisaran persentase antara 29,76-77,5\%. Persentase peningkatan DO tertinggi pada konsentrasi $25 \%$ sebesar $77,50 \%$. Nilai Dissolved Oxygen (DO) mengalami penurunan pada hari terakhir perlakuan (10 hari) menjadi 1,60-2,90 $\mathrm{mg} / 1$ dengan persentase penurunan sebesar 31,48-47,88\% (Tabel 2). Hasil analisis Anava pada hari ke-10 perlakuan kabomba berpengaruh nyata terhadap nilai DO $(\mathrm{F}=5,075 \mathrm{p}=0,009$; Anava). Semua perlakuan pada hari ke-10 berbeda nyata dengan kontrol tetapi tidak berbeda nyata antar perlakuan.

Hasil pengukuran kadar Chemical Oxygen Demand (COD) limbah cair laboratorium mengalami kenaikan selama 10 hari perlakuan. Kadar COD pada hari ke-0 berada pada kisaran 136- $4.820 \mathrm{mg} / \mathrm{L}$. Kadar COD hari ke-5 mengalami kenaikan pada kisaran 175- 9.490 $\mathrm{mg} / \mathrm{L}$. Kadar (COD) pada hari ke-10 mengalami penurunan pada konsentrasi $0 \%$ (kontrol) namun mengalami peningkatan pada konsentrasi 25,50 , 75 dan $100 \%$. Peningkatan tertinggi terjadi pada konsentrasi $50 \%$ dan terendah pada konsentrasi $100 \%$ dengan kisaran persentase 14,96 - 22,36\% (Tabel 3). Derajat keasaman $(\mathrm{pH})$ limbah cair laboratorium pada hari pertama perlakuan (0 hari) 
berada pada kisaran 2,5 -5,8, dan mengalami penurunan pada hari ke-10 dengan kisaran 1,1 5,5 (Tabel 4).

Tabel 3. Rerata Chemical Oxygen Demand (COD) limbah cair laboratorium setelah 10 hari perlakuan.

\begin{tabular}{cccc}
\hline Konsentrasi & \multicolumn{3}{c}{ Nilai COD $(\mathrm{mg} / \mathrm{L})$} \\
\cline { 2 - 4 } Perlakuan $(\%)$ & H ke-0 & H ke-5 & H ke-10 \\
\hline 0 & 136 & 175 & 60 \\
25 & 1.137 & 1.245 & 1.447 \\
50 & 2.250 & 4.740 & 5.800 \\
75 & 3.120 & 6.590 & 7.970 \\
100 & 4.820 & 9.490 & 10.910 \\
\hline
\end{tabular}

Tabel 4. Rerata Derajat Keasaman (pH)limbah cair laboratorium setelah 10 hari perlakuan.

\begin{tabular}{ccc}
\hline $\begin{array}{c}\text { Konsentrasi } \\
\text { Perlakuan }(\%)\end{array}$ & pH awal & pH akhir \\
\hline 0 & 5,8 & 5,5 \\
25 & 3,1 & 1,9 \\
50 & 2,95 & 1,6 \\
75 & 2,7 & 1,6 \\
100 & 2,5 & 1,4 \\
\hline
\end{tabular}

\section{Pembahasan}

Limbah cair laboratorium sebelum perlakuan dengan tumbuhan kabomba mengandung Total Suspended Solid (TSS) dan COD yang tinggi serta Dissolved Oxygen (DO) yang rendah. Hasil pengukuran TSS dan DO masing-masing mengalami penurunan dan peningkatan pada 5 hari perlakuan (Tabel 1 dan Tabel 2), sedangkan COD mengalami peningkatan setelah 10 hari perlakuan (Tabel 3).

TSS pada hari ke-5 mengalami penurunan dengan kisaran 5,75-25,25 $\mathrm{mg} / \mathrm{L}$ dan rentang persentase penurunan 29,36\%-37,67\%, sedangkan DO mengalami peningkatan pada kisaran 2,45-5,45 $\mathrm{mg} / \mathrm{L}$ dengan persentase sebesar 29,76-77,50\%. Persentase penurunan TSS dan peningkatan DO tertinggi terjadi pada konsentrasi perlakuan 25\% dengan penurunan TSS sebesar 37,67\% (Tabel 1) dan peningkatan DO sebesar 77,5\% (Tabel 2).

Kondisi ini diduga karena sifat hidup tumbuhan kabomba submerged (terendam) dengan seluruh organ atau biomassa sebagian tanaman kontak langsung dengan limbah. Tumbuhan kabomba mampu mengadsorbsi partikulat dengan memanfaatkan seluruh organnya (akar, batang dan daun) sehingga mampu menurunkan nilai TSS pada media perlakuan. Menurut Sudiro \& Agnes (2013) tanaman terendam seperti Hydrilla verticillata lebih baik dalam menyerap TSS dalam air limbah karena selain memanfaatkan akar, juga memanfaatkan daun dan batangnya yang ikut terendam, sementara tanaman mengapung seperti Lemna minor hanya memanfaatkan akarnya.

Nilai TSS mengalami kenaikan pada hari terakhir (hari ke-10) perlakuan pada kisaran 8,00-47,75 $\mathrm{mg} / \mathrm{L}$ dengan persentase kenaikan sebesar 42,73\%-160,06\% (Tabel 1), dan DO mengalami penurunan di hari yang sama (hari ke-10) pada kisaran 1,60-2,90 $\mathrm{mg} / \mathrm{L}$ dengan persentase penurunan sebesar 31,48\%-47,88\% (Tabel 2). Hasil ini mengindikasikan bahwa waktu perlakuan atau kontak dengan limbah selama 10 hari mengakibatkan kerusakan pada organ tumbuhan kabomba (C.aquatica), sehingga tidak mampu untuk menurunkan TSS dan meningkatkan nilai DO. Bahan organik pada air limbah diduga ikut berperan dalam meningkatkan kandungan TSS dan penurunan nilai DO.

Hasil pengukuran Chemical Oxygen Demand (COD) selama 10 hari menunjukkan perlakuan dengan tumbuhan kabomba belum mampu memperbaiki kualitas COD pada limbah (Tabel 3). Menurut Lumaela et. al. (2013) COD merupakan jumlah total oksigen yang dibutuhkan untuk mengoksidasi bahan anorganik maupun organik secara kimiawi. Tingginya kadar COD diduga terjadi reaksi-reaksi kimia dalam limbah karena akumulasi komponen bahan kimia yang sangat beragam dalam limbah. Trisnawati et al.,(2016) menyatakan bahwa faktor tingginya nilai COD dalam limbah cair laboratorium disebabkan oleh pemakaian bahan-bahan kimia selama kegiatan di laboratorium. Hasil penelitian menunjukkan penurunan nilai DO pada limbah berkaitan dengan tingginya kadar COD yang terkandung dalam limbah. Menurut Suparjo (2009) bahwa kandungan COD yang berlebihan akan berpengaruh terhadap menurunnya kandungan oksigen terlarut (DO) dan $\mathrm{pH}$, karena oksigen yang dibutuhkan untuk mengoksidasi zat organik besar maka kadar DO yang terlarut dalam air menjadi kecil.

Hasil pengukuran derajat keasaman $(\mathrm{pH})$ menunjukkan air limbah bersifat asam dengan kisaran $\mathrm{pH}$ 2,5-3,1 dan setelah perlakuan selama 10 hari mengalami penurunan pada kisaran 1,41,9 (Tabel 4). Nilai tersebut menunjukkan bahwa tumbuhan kabomba belum optimal dalam menaikkan kadar $\mathrm{pH}$ sehingga belum memenuhi standar baku mutu untuk pengelolaan dan pengendalian pencemaran air. Proses dekomposisi bahan organik dari tumbuhan yang mati akibat terganggunya proses fotosintesis juga diduga ikut 
berperan dalam menurunkan nilai $\mathrm{pH}$. Murphy (2005) selama proses dekomposisi bahan organik karbon dioksida akan dilepaskan sebagai produk akhir ke lingkungan dan menyebabkan penurunan kadar $\mathrm{pH}$ di suatu perarian.

\section{DAFTAR PUSTAKA}

Audiana, M, Apriani, I, \& Kadaria, U, 2017, Pengolahan Limbah Cair Laboratorium Teknik Lingkungan dengan Koagulasi dan Adsorpsi untuk Menurunkan $\mathrm{COD}, \mathrm{Fe}$ dan $\mathrm{Pb}$, Jurnal Program Studi Teknik Lingkungan Jurusan Teknik Sipil Fakultas Teknik Universitas Tanjungpura Pontianak, vol 1, no 1, hal $1-10$

Hanafiah, KA, 2004, Rancangan Percobaan: Teori dan Aplikasi, Fakultas Pertanian, Universitas Sriwijaya Palembang, Raja Grafindo, Jakarta

Hartini E, Yuantari MGC, 2011, Pengelolaan Air Limbah Laboratorium dengan menggunakan Koagulan Alum Sulfat dan Poly Alum Chloride di Laboratorium Kesehatan Universitas Dian Nuswantoro Semarang

Juswardi, Sagala, EP \& Ferdini, LA, 2010, 'Pertumbuhan Neptunia oleracea Lour. Pada Limbah Cair Amoniak dari Industri Pupuk UREA sebagai Upaya Pengembangan Fitoremediasi', Jurnal Penelitian Sains, vol 13, no 1, hal 1720

Kvesitadze, G, Khatisashvili, G, Sadunishvili, T \& Ramsden JJ, 2006, Biochemical Mechanisms of Detoxification in Higher Plants, Springer-Verlag Berlin, Germany

Lumaela AK, Otok BW, dan Sutikno, 2013, Pemodelan Chemical Oxygen Deman (COD) Sungai di Surabaya Dengan Metode Mixed Geographically Wighted Regression. Jurnal Sains dan Seni Pomit. vol. 2, hal 100-105

Murphy, Sheila, 2007, City of Boulder USGS water quality monitoring, Reasearch Analyst, BASIN Project city of Boulder

Othman MS, Lim EC \& Mushrifah I, Water Quality Changes in Chini Lake.
Environ. Monit Assess, 2007,131: 279292

Rohaeti, E, Nenny, FT \& Imadia B, 2011, Pengolahan Limbah Cair dari Kegiatan Praktikum Analisis Spot Test Dengan Koagulasi Menggunakan Polialuminium Klorida, Prosiding Seminar Nasional Teknologi Pengelolaan Limbah IX

Sheila Murphy, 2005, Diurnal Variations of Water Quality Parameters in Boulder Creek. http://bcn.boulder.co.us/basin/data/COB $\mathrm{WQ} /$ diurnal/index.html\#pH, diakses 4 Juli 2019

Sudiro \& Agnes, TA, 2013, Kajian Efektifitas Tanaman Air Lemna minor dan Hydrilla verticillata dalam Mereduksi BOD dan COD sebagai Upaya Perbaikan Kualitas Limbah Cair Industri Tahu, Jurnal Spectra, Jurusan Teknik Lingkungan Institut Teknologi Nasional, Malang, vol 11 , no 21, hal 53-67

Suparjo, M, N, 2009, Kondisi Pencemaran Perairan Sungai Babon Semarang. Jurnal Saintek Perikanan., vol 4, no 2, hal $38-45$

Suprihatin \& Siswi, IN, 2010, Penyisihan Logam Berat dari Limbah Cair Laboratorium dengan Metode Presipitasi dan Adsorpsi. Makara Sains. vol 14, no 1, hal 44-50

Tati, R, 2017, 'Penurunan Kadar Total Suspended Solid (TSS) Air Limbah Pabrik Tahu dengan Metode Fitoremediasi Menggunakan Tanaman Hydrilla verticillata', Jurnal Permukiman vol 12, no 1 , hal 25-32

Trisnawati N, Manuaba P \& Iryanti ES, 2016, Fitodegradasi dengan Tanaman Pacing (Speciosus cheilocostus) untuk Menurunkan Kandungan $\mathrm{Pb}, \mathrm{Cd}$,dan $\mathrm{Hg} / /$ Limbah Cair Laboratorium, Jurnal Cakra Kimia, vol 4, no 1, hal 77-83

Widyawati, Y, R, 2014. Efektivitas Lumpur Aktif (Activated Sludge) Dalam Menurunkan Nilai BOD (Biological Oxygen Demand) Pada Limbah Cair UPT. Lab Analitik Universitas Udayana. Skripsi. Jurusan Kimia Universitas Udayana. Jimbaran 